\title{
Модификация электронных свойств поверхности $n$-InP(100) сульфидными растворами
}

\author{
(С) М.В. Лебедев, Т.В. Львова, А.Н. Смирнов, В.Ю. Давыдов \\ Физико-технический институт им. А.Ф. Иофрфе Российской академии наук, \\ 194021 Санкт-Петербург, Россия \\ E-mail: mleb@triat.ioffe.ru
}

Поступила в Редакцию 12 апреля 2021 г.

В окончательной редакции 19 апреля 2021 г.

Принята к публикации 19 апреля 2021 г.

\begin{abstract}
Электронные свойства пассивированных различными сульфидными растворами поверхностей $n$-InP $(100)$ изучались с помощью методов фотолюминесценции и спектроскопии комбинационного рассеяния света. Показано, что процесс пассивации приводит к возрастанию интенсивности фотолюминесценции полупроводника, свидетельствующему о снижении скорости поверхностной безызлучательной рекомбинации, сопровождаемому сужением приповерхностной области пространственного заряда и увеличением электронной плотности в анализируемом объеме полупроводника. Эффективность электронной пассивации поверхности $n$-InP(100) зависит от состава сульфидного раствора.
\end{abstract}

Ключевые слова: фосфид индия, модификация поверхности, сульфидная пассивация, спектроскопия комбинационного рассеяния света, фотолюминесценция.

DOI: 10.21883/FTP.2021.10.51440.39

\section{1. Введение}

Фосфид индия (InP) - это один из важнейших полупроводников $\mathrm{A}^{\mathrm{III}} \mathrm{B}^{\mathrm{V}}$, широко используемый в современной электронике [1], оптоэлектронике [2], а также в устройствах преобразования солнечной энергии [3]. Благодаря прямой запрещенной зоне, высокой подвижности электронов и сравнительно низкой скорости поверхностной рекомбинации [4] фосфид индия является перспективным материалом для использования в полупроводниковых наноструктурных приборах [5-8].

Характеристики современных полупроводниковых приборов в существенной степени определяются свойствами поверхностей и интерфейсов. Как правило, поверхности полупроводников $\mathrm{A}^{\mathrm{III}} \mathrm{B}^{\mathrm{V}}$ характеризуются высокой плотностью состояний в запрещенной зоне, вызывающих закрепление (пиннинг) уровня Ферми и безызлучательную поверхностную рекомбинацию. Кроме того, полупроводники $\mathrm{A}^{\mathrm{III}} \mathrm{B}^{\mathrm{V}}$ химически активны и даже после кратковременного контакта с воздухом на поверхности формируется аморфный многокомпонентный оксидный слой толщиной в несколько нанометров, вызывающий появление дополнительных поверхностных состояний. Поэтому пассивация поверхности часто оказывается необходимой для снижения скорости поверхностной рекомбинации и сопутствующих электронных и оптических потерь. Одним из наиболее часто используемых методов пассивации поверхности полупроводников $\mathrm{A}^{\mathrm{III}} \mathrm{B}^{\mathrm{V}}$ является обработка сульфидными растворами или газами. В частности, сульфидная пассивация использовалась для модификации электронных свойств нанопроволок InP [9], а также интерфейсов InP/диэлектрик [10-12].

Как правило, сульфидная пассивация поверхности включает в себя удаление слоя естественного окисла и формирование пассивирующего покрытия, препятствующего повторному окислению поверхности и модифицирующего распределение плотности поверхностных состояний. В случае сульфидной пассивации поверхности $\operatorname{InP}(100)$ пассивирующее покрытие состоит в основном из сульфидов и оксидов индия [12-15]. Электронная пассивация поверхности проявляется в виде возрастания интенсивности краевой фотолюминесценции (ФЛ), свидетельствующего о снижении скорости поверхностной безызлучательной рекомбинации [12-15]. Однако причины снижения скорости безызлучательной рекомбинации на поверхности $n-\operatorname{InP}(100)$ посредством сульфидной пассивации остаются неясными, так как сведения о зонной структуре поверхности $n$ - $\operatorname{In} \mathrm{P}(100)$ довольно противоречивы. В ряде работ было показано, что изгиб зон на покрытой слоем естественного окисла поверхности составляет $\sim 0.3-0.4$ эВ $[16,17]$, как на чистой поверхности $n-\operatorname{InP}(100)-(2 \times 4)$, приготовленной методом молекулярно-пучковой эпитаксии [18], однако в некоторых случаях наблюдалось практически полное отсутствие изгиба зон на такой поверхности $n-\operatorname{InP}(100)[14,19,20]$. Такое различие электронной структуры окисленной поверхности $n-\operatorname{InP}(100)$ может быть обусловлено разностью методов подготовки поверхности и, соответственно, разным фазовым составом окисного слоя. Обработка полупроводника сульфидным раствором в общем случае должна приводить к изменению электронной зонной структуры его поверхности. Тем не менее, несмотря на наблюдаемое возрастание интенсивности ФЛ после обработки $n-\operatorname{InP}(100)$ водным раствором сульфида натрия, положение уровня Ферми на поверхности после пассивации не изменялось $[14,15]$.

С другой стороны, спиртовые сульфидные растворы часто показывают бо́льшую эффективность пас- 
Параметры спектров ФЛ и КРС исследованных образцов $n$-InP(100), а также оцененные из них значения концентрации свободных электронов $(n)$ и ширины обедненной области $(\delta)$

\begin{tabular}{|c|c|c|c|c|c|c|}
\hline $\begin{array}{c}\text { Образец } n \text {-InP }(100) \\
\text { (пассивирующий } \\
\text { раствор) }\end{array}$ & $\begin{array}{c}\text { Коэффициент возрастания } \\
\text { интенсивности ФЛ } \\
\text { после пассивации }\end{array}$ & $\begin{array}{c}\text { Положение } \\
\text { максимума } \\
\text { спектра ФЛ, эВ }\end{array}$ & $\begin{array}{c}\text { Положение } \\
\text { максимума } \\
\text { полосы } \mathrm{L}^{+}, \mathrm{cm}^{-1}\end{array}$ & $\begin{array}{c}\text { Значение } \\
\text { концентрации } \\
\text { электронов } n, \mathrm{~cm}^{-3}\end{array}$ & $\begin{array}{c}\text { Значение } \\
I(\mathrm{LO}) / I\left(\mathrm{~L}^{-}\right)\end{array}$ & $\delta, \mathrm{HM}$ \\
\hline $\begin{array}{l}\text { Необработанный } \\
1 \mathrm{M} \mathrm{Na}_{2} \mathrm{~S}_{\mathrm{aq}} \\
\left(\mathrm{NH}_{4}\right)_{2} \mathrm{~S}_{\mathrm{aq}}(4 \%) \\
\left(\mathrm{NH}_{4}\right)_{2} \mathrm{~S}+2 \mathrm{PA}(4 \%) \\
\left(\mathrm{NH}_{4}\right)_{2} \mathrm{~S}_{\mathrm{aq}}(44 \%)\end{array}$ & $\begin{array}{l}1 \\
2.7 \\
5.2 \\
6.2 \\
9\end{array}$ & $\begin{array}{l}1.350 \\
1.354 \\
1.354 \\
1.362 \\
1.365\end{array}$ & $\begin{array}{l}406 \\
462 \\
466 \\
680 \\
685\end{array}$ & $\begin{array}{l}5.1 \cdot 10^{17} \\
9.2 \cdot 10^{17} \\
9.6 \cdot 10^{17} \\
2.9 \cdot 10^{18} \\
3.0 \cdot 10^{18}\end{array}$ & $\begin{array}{l}2.63 \\
0.67 \\
0.47 \\
0.41 \\
0.33\end{array}$ & $\begin{array}{r}26.0 \\
10.0 \\
7.4 \\
6.5 \\
5.4\end{array}$ \\
\hline
\end{tabular}

сивации, чем водные растворы [21]. В данной работе с помощью микро-ФЛ и спектроскопии комбинационного рассеяния света с микронным разрешением (микро-КРС) исследовались электронные свойства поверхности $n-\operatorname{InP}(100)$ до и после обработки различными сульфидными растворами.

\section{2. Методика эксперимента}

Образцы изготавливались из пластины $n-\operatorname{InP}(100)$ с уровнем легирования $\sim 10^{18} \mathrm{~cm}^{-3}$, предварительная очистка которой осуществлялась посредством кипячения в толуоле и ацетоне с последующей промывкой в воде [14]. Полученные после предварительной очистки пластины образцы обрабатывались на воздухе сульфидными растворами. В качестве сульфидных растворов использовались растворы сульфида аммония $\left(\left(\mathrm{NH}_{4}\right)_{2} \mathrm{~S}\right)$, приготовленные из стандартного водного раствора сульфида аммония $\left(\left(\mathrm{NH}_{4}\right)_{2} \mathrm{~S} \quad(40-48\right.$ вес\% в $\mathrm{H}_{2} \mathrm{O}$ ), Merck-Sigma-Aldrich). Первый образец обрабатывался стандартным раствором $\left(\mathrm{NH}_{4}\right)_{2} \mathrm{~S}(\sim 44 \%)$ в течение 10 мин при комнатной температуре. Второй и третий образцы обрабатывались в течение 10 мин при комнатной температуре растворами сульфида аммония, приготовленными из стандартного путем разбавления водой или изопропиловым спиртом (2-РА) в соотношении 1:9 так, чтобы объемная концентрация сульфидов составляла $\sim 4 \%$ [22]. Кроме того, для сравнения, четвертый образец обрабатывался $1 \mathrm{M}$ водным раствором сульфида натрия $\left(\mathrm{Na}_{2} \mathrm{~S} \cdot 9 \mathrm{H}_{2} \mathrm{O}\right.$, Merck-Sigma-Aldrich) при температуре $\sim 40^{\circ} \mathrm{C}$ в течение 1 мин [14]. После сульфидной обработки каждый образец промывался водой (либо изопропиловым спиртом для образца, обработанного спиртовым сульфидным раствором) и высушивался на воздухе. В качестве эталона изучался необработанный образец, подвергнутый только предварительной очистке.

Исследования методами микро-ФЛ и микро-КРС необработанного и пассивированных образцов производились при комнатной температуре с помощью спектрометра T64000 (Horiba Jobin-Yvon, Lille, France), снабженного конфокальным микроскопом. Спектры возбуждались линией $\mathrm{He}-\mathrm{Cd}$-лазера (Plasma, Inc., Russia) с длиной волны $\lambda=442$ нм (2.81 эВ). При выполнении
микро-ФЛ исследований диаметр светового пятна составлял $\sim 1$ мкм и плотность мощности лазерного излучения не превышала $50 \mathrm{BT} / \mathrm{cm}^{2}$. Исследования методом микро-КРС производились из той же точки образца, что и микро-ФЛ исследования, при этом плотность мощности лазерного излучения составляла $\sim 5.5 \mathrm{\kappa BT} / \mathrm{cm}^{2}$.

\section{3. Результаты и их обсуждение}

Спектры ФЛ необработанного (покрытого слоем естественного окисла) и пассивированных образцов представлены на рис. 1, $a$. Спектр необработанного образца представляет собой асимметричный пик с максимумом $\sim 1.35$ эВ, что несколько больше ширины запрещенной зоны InP при комнатной температуре $(1.344$ эВ $[23,24])$, но соответствует разности энергий уровня Ферми и края валентной зоны в объеме материала с данным уровнем легирования [25].

После пассивации любым раствором интенсивность ФЛ $n$-InP(100) возрастала (см. рис. 1, $a$ и таблицу), т.е. обработка каждым из рассматриваемых растворов приводит к электронной пассивации поверхности $n-\operatorname{InP}(100)$ и снижению на ней скорости безызлучательной рекомбинации. При этом максимум спектра ФЛ после пассивации сдвигался в сторону бо́льших энергий (см. рис. 1, $a$ и таблицу). Так как, согласно данным работы [25], энергия максимума ФЛ $n$-InP соответствует разнице энергий уровня Ферми и края валентной зоны в объеме полупроводника, то сдвиг максимума ФЛ в сторону бо́льших энергий свидетельствует о сдвиге уровня Ферми в объеме полупроводника глубже в зону проводимости, т. е. об увеличении электронной плотности в анализируемом объеме полупроводника. Наибольшее возрастание интенсивности ФЛ и, соответственно, более эффективная электронная пассивация поверхности наблюдались после обработки в концентрированном (стандартном) водном растворе $\left(\mathrm{NH}_{4}\right)_{2} \mathrm{~S}$, а также в спиртовом растворе $\left(\mathrm{NH}_{4}\right)_{2} \mathrm{~S}$.

Спектры КРС образцов $n-\operatorname{InP}(100)$ до и после обработки различными сульфидными растворами представлены на рис. $1, b$. Спектры измерялись в геометрии обратного рассеяния, которая в обозначениях Порто имеет вид: 


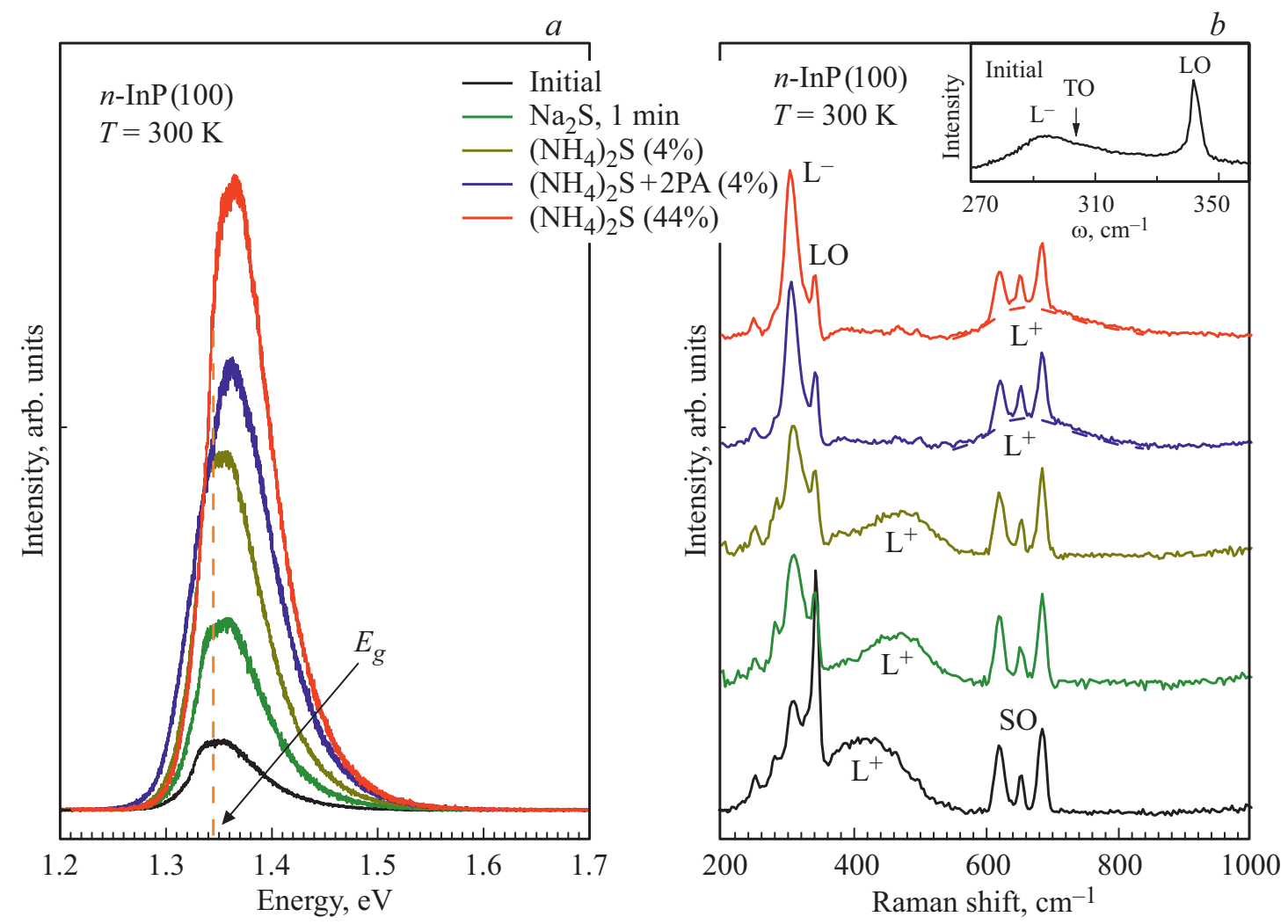

Рис. 1. Спектры ФЛ $(a)$ и КРС $(b) n$-InP(100), измеренные до и после пассивации различными сульфидными растворами. На вставке рис. $1, b$ представлен спектр КРС необработанного образца, демонстрирующий соотношение положений $\mathrm{L}^{-}$-моды и ТО-фонона. (Цветной вариант рисунка представлен в электронной версии статьи).

$z(x x) \bar{z}$ (здесь ось $z$ направлена перпендикулярно поверхности образца, а ось $x$ - ортогональна ей). В полярных материалах, таких, как InP, продольные оптические (LO) фононы могут взаимодействовать через макроскопическое электрическое поле с коллективными возбуждениями свободных носителей (плазмонами). Это приводит к образованию двух мод, носящих смешанный плазмонфононный характер, частоты которых сильно зависят от концентрации $(n)$ свободных носителей $\left(\mathrm{L}^{-}-\right.$и $\mathrm{L}^{+}$-моды). Изучение энергетического положения смешанных мод с использованием различных моделей дает возможность оценить концентрацию свободных носителей заряда в InP [26-28].

Спектр КРС необработанного образца имеет вид, типичный для легированного $n-\operatorname{InP}(100)$ [26]. В спектре наблюдается пик LO-фонона $\left(343 \mathrm{~cm}^{-1}\right)$, связанный с рассеянием в приповерхностной области пространственного заряда; три пика в области $600-700 \mathrm{~cm}^{-1}$, которые относятся к спектру КРС второго порядка (на рис. $1, b$ они обозначены как $\mathrm{SO})$; а также пик $\mathrm{L}^{-}$-моды $\left(\sim 290 \mathrm{~cm}^{-1}\right)$ и широкая полоса $\mathrm{L}^{+}$-моды $\left(\sim 430 \mathrm{~cm}^{-1}\right)$, обусловленные рассеянием в объеме полупроводника. Как видно на вставке рис. $1, b$, положение $\mathrm{L}^{-}$-моды для исходного образца $\left(\sim 290 \mathrm{~cm}^{-1}\right)$ близко к положению TO-фонона InP $\left(303.5 \mathrm{~cm}^{-1}\right)$, что указывает на то, что концентрация электронов $n>10^{16} \mathrm{~cm}^{-3}$ и чувствитель- ность $\mathrm{L}^{-}$-моды к изменениям величины концентрации будет очень слабая [28]. В свою очередь $\mathrm{L}^{+}$-мода наиболее чувствительна к изменениям электронной плотности в диапазоне $n>10^{17} \mathrm{~cm}^{-3}$. Для оценки $n$ мы использовали график, связывающий положение линии $\mathrm{L}^{+}$-моды в зависимости от $n$, который рассчитан с использованием гидродинамической модели и приведен на рис. 3 работы [28]. Положение максимума полосы $\mathrm{L}^{+}$-моды в спектре необработанного $n$-InP $\left(\sim 406 \mathrm{~cm}^{1}\right)$ соответствует концентрации электронов $5.1 \cdot 10^{17} \mathrm{~cm}^{-3}$ в объеме (см. таблицу).

После сульфидной обработки спектры КРС слоев $n$-InP $(100)$ существенно изменились (рис. $1, b)$. Видно, что максимум полосы $\mathrm{L}^{+}$-моды сдвинулся в сторону более высоких частот, причем тем сильнее, чем сильнее возрастала интенсивность ФЛ. Так как полоса $\mathrm{L}^{+}$-моды чувствительна к плотности электронов в объеме полупроводника, увеличение волнового числа максимума этой полосы свидетельствует о возрастании плотности электронов в анализируемом объеме $n$-InP после сульфидной обработки. Волновые числа максимумов полосы $\mathrm{L}^{+}$-моды в спектрах КРС рассматриваемых образцов и оцененные из них величины электронной плотности, полученные с использованием упомянутого выше графика из работы [28], суммированы в таблице. Эти данные хорошо согласуются с результатами ФЛ измерений, где 
сдвиг максимума полосы ФЛ (см. рис. $1, a$ и таблицу) свидетельствует об увеличении электронной плотности в объеме полупроводника. При этом положение максимума спектра ФЛ коррелирует с положением максимума полосы $\mathrm{L}^{+}$-моды в спектрах КРС (см. таблицу).

Присутствие пика LO-фонона в спектрах KPC (рис. $1, b$ ) указывает на наличие в рассматриваемых образцах $n$-InP(100) приповерхностной обедненной области и, соответственно, изгиба зон (рис. 2), появляющихся из-за захвата носителей заряда из объема полупроводника поверхностными состояниями. В качестве состояний могут выступать любые неоднородности поверхности, например, ступени и изломы ступеней, оборванные связи, чужеродные атомы и т.п. $[18,19]$. Более высокая плотность поверхностных состояний приводит к большей ширине обедненной области $\delta$. Как правило, плотность поверхностных состояний в запрещенной зоне $n-\operatorname{InP}(100)$ составляет $\sim 10^{12} \mathrm{~cm}^{-2}$ эB $^{-1}[12]$.

Уменьшение интенсивности пика LO-фонона в спектрах КРС образцов $n$-InP после обработки сульфидными растворами (рис. $1, b$ ) свидетельствует об уменьшении приповерхностной обедненной области (см. таблицу) и, соответственно, о снижении плотности заполненных поверхностных состояний (рис. 2). Действительно, после сульфидной пассивации плотность состояний в запрещенной зоне $n$-InP $(100)$ может снижаться на $\sim 2$ порядка [12]. Используя соотношения интенсивностей пиков LO-фонона и $\mathrm{L}^{-}$-моды (см. рис. $1, b$ и таблицу), можно рассчитать значения ширины обедненной области $\delta$ по методике, предложенной в работах $[29,30]$. Для этого вначале рассчитывалось значение $\delta_{0}$ для необработанной поверхности $n$-InP(100) по формуле

$$
\delta_{0}=\sqrt{\frac{\varepsilon_{0} V_{B}}{2 \pi n e^{2}}},
$$

где $\varepsilon_{0}-$ статическая диэлектрическая постоянная InP, $V_{B}$ - величина приповерхностного изгиба зон, $n-$ концентрация электронов в объеме полупроводника (см. таблицу), а $e$ - заряд электрона. В качестве величины приповерхностного изгиба зон на необработанной (покрытой слоем естественного окисла) поверхности $n$-InP $(100)$ использовалось значение 0.35 эВ [16]. Затем из данных для спектра КРС необработанного полупроводника (см. рис. $1, b$ и таблицу) определялось значение $I_{0}(\mathrm{LO}) / I_{0}\left(\mathrm{~L}^{-}\right)$для интенсивностей пиков LO-фонона и $\mathrm{L}^{-}$-моды в нелегированном полупроводнике по формуле

$$
\frac{I(\mathrm{LO})}{I\left(\mathrm{~L}^{-}\right)}=\frac{I_{0}(\mathrm{LO})}{I_{0}\left(\mathrm{~L}^{-}\right)} \times \frac{(1-\exp (-2 \alpha \delta))}{\exp (-2 \alpha \delta)},
$$

где $\alpha-$ коэффициент поглощения света с длиной волны 442 нм в InP [31], а в качестве $\delta$ используется значение $\delta_{0}$, полученное из формулы (1). После этого, используя полученное соотношение $I_{0}(\mathrm{LO}) / I_{0}\left(\mathrm{~L}^{-}\right)$, а также полученные из спектров КРС пассивированных образцов значения $I(\mathrm{LO}) / I\left(\mathrm{~L}^{-}\right)$, с помощью формулы (2)

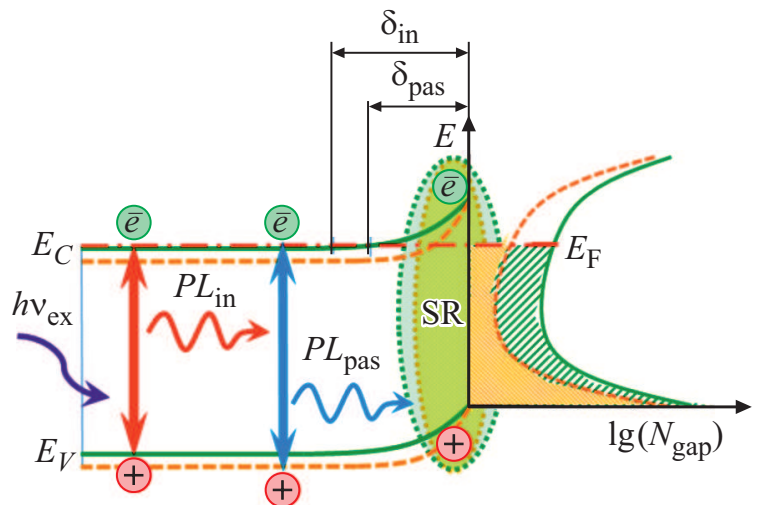

Рис. 2. Энергетическая диаграмма и распределение поверхностных состояний $\left(N_{\text {gap }}\right)$ для необработанной (зеленые линии) и пассивированной сульфидным раствором поверхности $n-\operatorname{InP}(100)$ (желтые пунктирные линии). $\delta_{\text {in }}$ и $\delta_{\text {pas }}-$ значения ширины приповерхностной обедненной области для необработанной и пассивированной поверхности соответственно. SR канал поверхностной безызлучательной рекомбинации; $h v_{\mathrm{ex}}-$

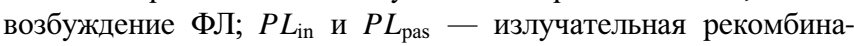
ция $(Ф Л)$ в необработанном и пассивированном $n-\operatorname{InP}(100)$ соответственно. (Цветной вариант рисунка представлен в электронной версии статьи).

вычислялись значения $\delta$ для пассивированных поверхностей $n$-InP(100).

Снижение плотности поверхностных состояний после сульфидной пассивации происходит в результате перестройки поверхностных связей. Локализованный на исчезающих поверхностных состояниях заряд может уходить в раствор, вследствие чего будет уменьшаться заряд поверхности, а следовательно, и ширина обедненной области $\delta$. Механизм переноса заряда из полупроводника в раствор будет в существенной степени определяться реакционной способностью компонентов раствора [21], что может объяснить наблюдаемую зависимость эффективности электронной пассивации поверхности $n$-InP $(100)$ от состава сульфидного раствора (см. рис. 1 и таблицу). В частности, возрастание интенсивности ФЛ в образцах $n$-InP(100) после пассивации спиртовым раствором $\left(\mathrm{NH}_{4}\right)_{2} \mathrm{~S}$ заметно выше, чем возрастание интенсивности ФЛ после пассивации водным раствором $\left(\mathrm{NH}_{4}\right)_{2} \mathrm{~S}$ такой же концентрации. При этом разница в соответствующих спектрах КРС (уменьшение интенсивности пика LO-фонона и сдвиг максимума полосы $\mathrm{L}^{+}$-моды) становится еще более заметной (рис. $\left.1, b\right)$. Это согласуется с данными для поверхностей $n-\mathrm{GaAs}(100)$, пассивированных растворами $\left(\mathrm{NH}_{4}\right)_{2} \mathrm{~S}$ в различных растворителях [21,32]. Кроме того, как было показано раньше, обработка раствором $\left(\mathrm{NH}_{4}\right)_{2} \mathrm{~S}$ в изопропиловом спирте приводила к более эффективной пассивации поверхности нанопроволок $p$-InP, чем обработка водным раствором сульфида аммония такой же концентрации [9].

Высокочастотный сдвиг полосы $\mathrm{L}^{+}$-моды в спектрах КРС (см. рис. $1, b$ и таблицу), а также сдвиг максимума 
ФЛ в сторону бо́льших энергий (см. рис. $1, a$ и таблицу) свидетельствуют о сдвиге уровня Ферми в объеме полупроводника глубже в зону проводимости (рис. 2). Эти эффекты коррелируют со степенью возрастания интенсивности ФЛ после сульфидной обработки (см. таблицу), т.е. со скоростью поверхностной рекомбинации (рис. 2).

Глубина проникновения лазерного излучения с длиной волны 442 нм, используемого для возбуждения ФЛ и спектров КРС, составляет $\sim 45$ нм [31]. В свою очередь сульфидная обработка оказывает влияние только на сравнительно тонкий приповерхностный слой InP толщиной в несколько монослоев (1-2 нм) [14]. Так как обработка сульфидными растворами производится при комнатной температуре, диффузию атомов серы с поверхности в объем InP можно полностью исключить. Поэтому изменение электронной плотности в объеме полупроводника не может быть связано с изменением уровня легирования после пассивации сульфидным раствором. С другой стороны, возрастание электронной плотности в объеме $n$-InP после пассивации может быть обусловлено изменением концентрации дырочных ловушек на поверхности, благодаря которым при возбуждении могут появляться дополнительные свободные электроны [33]. Тем не менее для однозначного установления причины увеличения электронной плотности в объеме полупроводника после пассивации его поверхности требуются дополнительные экспериментальные и теоретические исследования, которые в настоящий момент планируются.

\section{4. Заключение}

Пассивация поверхности $n-\operatorname{In} \mathrm{P}(100)$ различными сульфидными растворами исследовалась с помощью ФЛ и спектроскопии КРС. Было показано, что после сульфидной обработки интенсивность ФЛ $n$ - $\operatorname{InP}(100)$ возрастает, что свидетельствует об электронной пассивации поверхности. Возрастание интенсивности ФЛ сопровождается изменениями в спектрах КРС, указывающими на существенное уменьшение ширины приповерхностной обедненной области и возрастание плотности электронов в анализируемом объеме $n$-InP. Эффективность электронной пассивации поверхности $n$ - $\operatorname{InP}(100)$ зависит от состава сульфидного раствора. Наибольший эффект достигался при обработке поверхности раствором $\left(\mathrm{NH}_{4}\right)_{2} \mathrm{~S}$ в изопропиловом спирте, или концентрированным водным раствором $\left(\mathrm{NH}_{4}\right)_{2} \mathrm{~S}(44 \%)$.

\section{Финансирование работы}

Работа частично поддержана Российским фондом фундаментальных исследований (РФФИ) (проект № 20-03-00523).

\section{Конфликт интересов}

Авторы заявляют, что у них нет конфликта интересов.

\section{Список литературы}

[1] J.A. del Alamo. Nature, 479, 317 (2011).

[2] M. Smit, K. Williams, J. van derTol. APL Photonics, 4, 050901 (2019).

[3] Q. Lin, D. Sarkar, Y. Lin, M. Yeung, L. Blankemeier, J. Hazra, W. Wang, S. Niu, J. Ravichandran, Z. Fan, R. Kapadia. ACS Nano, 11, 5113 (2017).

[4] H.J. Joyce, J. Wong-Leung, C.-K. Yong, C.J. Docherty, S. Paiman, Q. Gao, H.H. Tan, C. Jagadish, J. Lloyd-Hughes, L.M. Herz, M.B. Johnston. Nano Lett., 12, 5325 (2012).

[5] X. Duan, Y. Huang, Y. Cui, J. Wang, C.M. Lieber. Nature, 409, 66 (2001).

[6] F. Zafar, A. Iqbal. Proc. Royal Soc. A, 472, 20150804 (2016).

[7] Z. Li, I. Yang, L. Li, Q. Gao, J.S. Chong, Z. Li, M.N. Lockrey, H.H. Tan, C. Jagadish, L.Fu. Prog. Nat. Sci. Mater., 28, 178 (2018).

[8] Z. Wu, P. Liu, W. Zhang, K. Wang, X.W. Sun. ACS Energy Lett., 5, 1095 (2020).

[9] N. Tajik, C.M. Haapamaki, R.R. LaPierre. Nanotechnology, 23, 315703 (2012).

[10] C.-F. Yen, M.-K. Lee. J. Vac. Sci. Technol. B, 30, 052201 (2012).

[11] H.-K. Kang, Y.-S. Kang, M. Baik, K.-S. Jeong, D.-K. Kim, J.-D. Song, M.-H. Cho. J. Phys. Chem. C, 122, 7226 (2018).

[12] D.H. van Dorp, L. Nyns, D. Cuypers, T. Ivanov, S. Brizzi, M. Tallarida, C. Fleischmann, P. Hönicke, M. Müller, O. Richard, D. Schmeißer, S. De Gendt, D.H.C. Lin, C. Adelmann. ACS Appl. Electron. Mater., 1, 2190 (2019).

[13] S. Tian, Z. Wei, Y. Li, H. Zhao, X. Fang, J. Tang, D. Fang, L. Sun, G. Liu, B. Yao, X. Ma. Mater. Sci. Semicond. Process., 17, 33 (2014).

[14] M.V. Lebedev, Yu.M. Serov, T.V. Lvova, R. Endo, T. Masuda, I.V. Sedova. Appl. Surf. Sci., 533, 147484 (2020).

[15] M.V. Lebedev, Yu.M. Serov, T.V. Lvova, I.V. Sedova, R. Endo, T. Masuda. Semiconductors, 54, 1843 (2020).

[16] J.M. Moison, M. Van Rompay, M. Bensoussan. Appl. Phys. Lett., 48, 1362 (1986).

[17] G. Chen, S.B. Visbeck, D.C. Law, R.F. Hicks. J. Appl. Phys., 91, 9362 (2002).

[18] Y. Ishikawa, T. Fukui, H. Hasegawa. J. Vac. Sci. Technol. B, 15, 1163 (1997)

[19] N. Newman, W.E. Spicer, T. Kendelewicz, I. Lindau. J. Vac. Sci. Technol. B, 4, 931 (1986).

[20] J.R. Waldrop, S.P. Kowalczyk, R.W. Grant. Appl. Phys. Lett., 42, 454 (1983).

[21] М.В. Лебедев. ФТП, 54, 587 (2020).

[22] М.В. Лебедев, Т.В. Львова, А.Л. Шахмин, О.В. Рахимова, П.А. Дементьев, И.В. Седова. ФТП, 53, 908 (2019).

[23] P. Lautenschlager, M. Garriga, M. Cardona. Phys. Rev. B, 36, 4813 (1987).

[24] L. Pavesi, F. Piazza, A. Rudra, J.F. Carlin, M. Ilegems. Phys. Rev. B, 44, 9052 (1991).

[25] R.M. Sieg, S.A. Ringel. J. Appl. Phys., 80, 448 (1996).

[26] L. Artús, R. Cuscó, J. Ibáñez, N. Blanco, G. González-Díaz. Phys. Rev. B, 60, 5456 (1999).

[27] B.H. Bairamov, I.P. Ipatova, V.A. Milorava, V.V. Toporov, K. Naukkarinen, T. Tuomi, G. Irmer, J. Monecke. Phys. Rev. B, 38, 5722 (1988).

[28] B.B. Boudart, B. Prévot, C. Schwab. Appl. Surf. Sci., 50, 295 (1991). 
[29] A. Pinczuk, A.A. Ballman, R.E. Nahory, M.A. Pollack, J.M. Worlock. J. Vac. Sci. Technol., 16, 1168 (1979).

[30] L.A. Farrow, C.J. Sandroff, M.C. Tamargo. Appl. Phys. Lett., 51, 1931 (1987).

[31] D.E. Aspnes, A.A. Studna. Phys. Rev. B, 27, 985 (1983).

[32] V. N. Bessolov, M.V. Lebedev, N.M. Binh, M. Friedrich, D.R.T. Zahn. Semicond. Sci. Technol., 13, 611 (1998).

[33] E.V. Ivanova, P.A. Dementev, T.V. Lvova, M.V. Lebedev. J. Phys.: Conf. Ser., 1697, 012061 (2020).

Редактор Г.А. Оганесян

\section{Modification of the $n-\ln P(100)$ surface electronic properties with sulfide solutions}

M.V. Lebedev, T.V. Lvova, A.N. Smirnov, V.Yu. Davydov

loffe Institute,

194021 St. Petersburg, Russia

Abstract Photoluminescence and Raman spectroscopy are used to study the electronic properties of $n-\operatorname{InP}(100)$ surfaces passivated with different sulfide solutions. Such a passivation results in the increase in photoluminescence intensity of the semiconductor evidencing for the reduction in the surface recombination velocity. The increase in the photoluminescence intensity is accompanied by the narrowing of the surface depletion layer, as well as by the increase of the electron density in the probed volume of InP. The efficiency of electronic passivation of the $n-\operatorname{InP}(100)$ surface depends on the composition of the sulfide solution. 